\title{
Determination of the Energy Capacity of Face Rock Breaking by the Geokhod's Knife Operating Element and its Dependence on the External Propeller's Pitch
}

\author{
Valery Nesterov$^{1}$, Vladimir Aksenov ${ }^{2}$, Vladimir Sadovets ${ }^{1}$, Dmitry Pashkov, ${ }^{3, *}$, and Zhadyra \\ Beysebayeva $^{4}$ \\ ${ }^{1}$ T.F. Gorbachev Kuzbass State Technical University, 650000, Kemerovo, Russia \\ ${ }^{2}$ Research Center "Siberian NPO", 650000, Kemerovo, Russia \\ ${ }^{3}$ Institute of Coal of the Federal Research Center Coal and Coal Chemistry Siberian Branch of the \\ RAS, 650610, Kemerovo, Russia \\ ${ }^{4}$ Kazakh Humanitarian-Law Innovative University, Semey, Kazakhstan
}

\begin{abstract}
Absract. The article contains a method for determination of the energy capacity of face rock breaking by the knife operating element of the geokhod. In addition, the dependence of the breaking energy capacity on the pitch of the geokhod's external propeller was revealed. The relevance of the study was considered. In order to set goals and objectives of the study, work features of new-class mining machines - geokhods and fundamental principles of geokhod technology were presented. Advantages and disadvantages of existing methods for determination of the energy capacity of rock breaking were identified, and the possibility of using them in calculation of power parameters of the geokhod's knife operating element was assessed. Power and geometrical parameters of the geokhod's knife operating element were determined, which affect the energy capacity of rock breaking. To determine the influence of the external propeller's pitch on the breaking energy capacity, geometrical parameters of the knife operating element and parameters of mining conditions of workings were substantiated. As a result of the study, it was revealed that the energy capacity of rock breaking by the knife operating element decreases nonuniformly as the pitch of the external propeller increases.
\end{abstract}

\section{Introduction}

Currently, a team of authors [1-6] are working on the development and creation of technical devices of a new class of shaft-sinking and tunneling technology - geokhods. These are machines that are designed to carry out underground workings of different purposes and spatial arrangement [7-9]. It is proposed to call the technology for formation of cavities in an underground space, in which the main element is the geokhod, as the geokhod technology.

\footnotetext{
${ }^{*}$ Corresponding author: pashkov.d.a@inbox.ru
} 
According to fundamental principles of the geokhod technology, the geokhod is considered as an underground device that simultaneously implements all key stages of cavity formation in an underground space.

When justifying engineering and design solutions of devices and elements of geokhods, it is required to take into account the screw motion of the machine at the face of workings. In addition, the complex nature of the geokhod's movement makes it necessary to consider dependencies of power and design parameters of geokhod's devices, both with the external environment and to each other.

One of geokhod's key elements that influences power parameters of the underground device is the operating element. In turn, design parameters of the geokhod's external propeller influences design and power parameters of the operating element.

At the current stage of the development of parameters of geokhod devices, there are urgent objectives to substantiate engineering and design solutions of operating elements for breaking of rocks of low hardness, and to develop methods for calculation and designing of its elements.

The principal criterion for evaluation of the operational efficiency of the geokhod's operating element is the energy capacity of rock breaking [10]. Therefore, works aimed at development of the method for calculation of the energy capacity of face rock breaking by the geokhod's operating element, as well as determination of the influence of design parameters of the external propeller on it are relevant.

There are various methods for determination of the energy capacity of rock breaking proposed by different authors, but the term "energy capacity of rock breaking" is generally accepted, and it means the quantity of work spent on breaking of a unit of volume or mass of a rock [11-16].

To develop the method for determination of the energy capacity of breaking of rocks of small hardness with the geokhod's knife operating element, article authors considered three existing approaches to determination of the energy capacity of mining and digging machinery.

The energy capacity of rock breaking by the rotor operating element $\left(H_{w}, \mathrm{~kW} \cdot \mathrm{h} / \mathrm{m}^{3}\right)$, based on the work of K.A. Ananyev, is determined as follows

$$
H_{w}=\frac{2 \pi M}{3600 W_{v o l}}
$$

where $M$ is the total moment spent on cutting, $\mathrm{kNm}$;

$W_{v o l}$ is the volume of destroyed rocks per one revolution, $\mathrm{m}^{3}$.

The energy capacity of rock breaking by the cutting tool $\left(H_{w}, \mathrm{MJ} / \mathrm{m}^{3}\right)$, based on the work of N.A. Malevich, is determined as follows

$$
H_{w}=\frac{Z}{t h},
$$

where $Z$ is the cutting force, $\mathrm{N}$;

$t$ is the destruction pitch, mm;

$h$ is the average chip thickness, mm.

$\mathrm{Yu}$.A. Vetrov proposed to determine the energy capacity of soil destruction by digging machines $\left(p, \mathrm{MJ} / \mathrm{m}^{3}\right)$ as follows

$$
p=\frac{P}{F_{a v}}
$$

where $P$ is the cutting force of the knife, N; 
$F_{a v}$ is the cross-section area of the cut, $\mathrm{mm}^{2}$.

Equations for determination of the energy capacity of rock breaking presented by N.A. Malevich and Yu.A.Vetrov are identical. In both equations, cutting forces are represented in the numerator, and N.A. Malevich uses the product of chip thickness by the destruction pitch in the denominator, which in essence is the cross-section area of the cut, and Yu.A. Vetrov immediately uses the cross-section area of the cut in the denominator.

It is worth noting that in Yu.A. Vetrov's equation, the value of the energy capacity of soil destruction by digging machines is called as the specific cutting force.

The first difference of the first method from the second and third is in the size of the energy capacity of rock breaking. However, when converting $\mathrm{kW} \cdot \mathrm{h}$ to $\mathrm{MJ}(1 \mathrm{~kW} \cdot \mathrm{h}=3.6 \mathrm{MJ})$ in equation (1), the coefficient in the denominator equal to 3,600 will be cancelled. And the equation (1) will be as follows

$$
H_{w}=\frac{2 \pi M}{1000 W_{\text {vol }}}
$$

The second difference of presented equations is that in the first method, the total moment spent on cutting is indicated in the numerator, and the volume of destroyed rocks per one revolution is shown in the denominator. In the second and third equations, the cutting force is shown in the numerator, and the cross-section area is indicated in the denominator.

The method for determination of power parameters of the geokhod's knife operating element [1-4] is based on determination of power parameters of operating elements by trial coefficients that Yu.A. Vetrov developed. Therefore, to substantiate the energy capacity of rock breaking by the geokhod's knife operating element, equations proposed by $\mathrm{Yu}$. A. Vetrov were taken to determine the specific energy capacity of rock breaking.

\section{Methods of research}

One of parameters that affect the breaking energy capacity is the cross-section area of the cut.

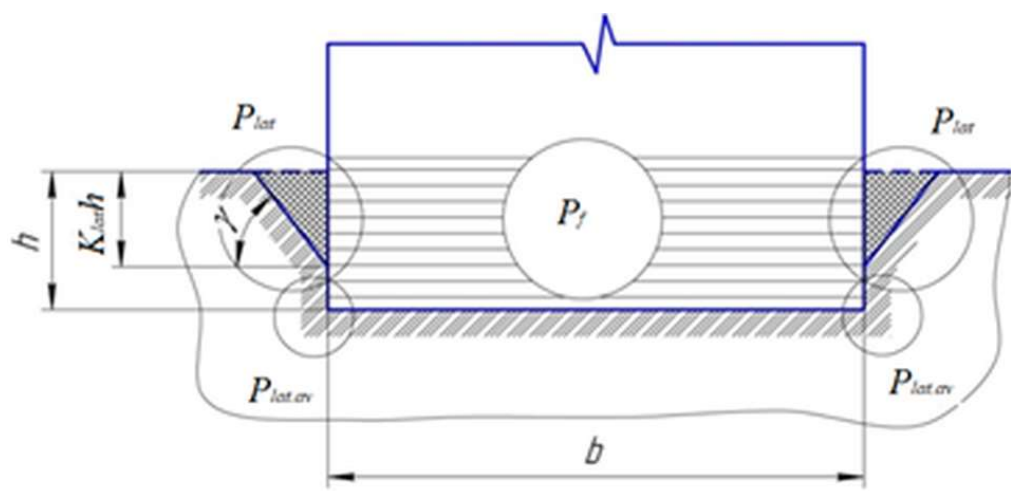

Fig. 1. Areas of operation of cutting force components of the sharp knife.

The cross-section area of the cut for the geokhod's knife operating element from Figure 1 will be determined as follows

$$
F_{a v}=b h+k_{\text {lat }}^{2} h^{2} \operatorname{ctg} \gamma
$$

where $b$ is the width of the knife, $\mathrm{m}$; $h$ is the depth of the cut, m; 
$k_{\text {lat }}$ is the depth coefficient of the expanding part of the cut; $\gamma$ is the angle of slope of the expanding part of the cut to the horizon, degree.

The second parameter is the power factor. Principal force parameters for the geokhod's knife operating element include: projection of the total force of soil resistance to cutting on the geokhod's rotation axis $P_{0}$ and on the plane perpendicular to the geokhod's rotation axis $R_{O E}$, and also the resistance moment to cutting from this component $M_{O E}$ [14-17]. The presented force factors are shown in Figure 2.

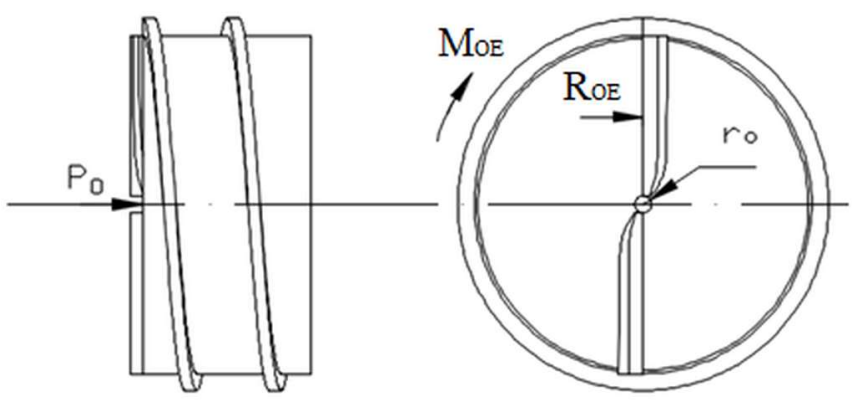

Fig. 2. Calculation model for determination of the total force of soil resistance to cutting by the knife operating element.

To determine the energy capacity of rock breaking by the geokhod's knife operating element, the cutting force $P$ in equation (3) will be equal to the projection of the total force of soil resistance to cutting on the plane perpendicular to the rotation axis of the geokhod $\mathrm{R}_{\mathrm{OE}}$. Consequently, the equation (3) will be as follows

$$
p=\frac{R_{O E}}{F_{a v}} \text {. }
$$

The total projection of the force of soil resistance to cutting on the plane perpendicular to the rotation axis for the geokhod's knife operating element is equal to [18-23]

$$
R_{\text {o.e }}=n\left(R_{\text {o.e.f }}+R_{\text {o.e.lat }}\right) \text {, }
$$

where $n$ is the number of knives of the geokhod's OE;

$R_{\text {o.e.f }}$ is is the projection of the force component of soil resistance to cutting, depending on the width of the cut, on the plane perpendicular to the rotation axis of the geokhod, $\mathrm{N}$;

$R_{\text {o.e.lat }}$ is the projection of the force component of soil resistance to cutting, not dependent on the width of the cut, on the plane perpendicular to the rotation axis of the geokhod, $\mathrm{N}$.

The projection of the force component of soil resistance to cutting, which depends on the width of the cut, on the plane perpendicular to the rotation axis of the geokhod [18-23]

$$
R_{\text {o.e.f }}=\frac{\varphi m_{f} h_{E}^{2}}{2 \pi n \operatorname{co}}\left[\frac{\left(\sin \beta_{2}-\sin \beta_{1}\right)}{\sin \beta_{2} \cdot \sin \beta_{1}}+\cot \left(\delta+\varphi_{f r}\right) \ln \left|\frac{\operatorname{tg} \frac{\beta_{2}}{2}}{\operatorname{tg} \frac{\beta_{1}}{2}}\right|\right],
$$

The projection of the force component of soil resistance to cutting, not dependent on the width of the cut, on the plane perpendicular to the rotation axis of the geokhod [18-23]

$$
R_{\text {o.e.lat }}=\frac{h_{E}}{n}\left(m_{\text {lat }} \frac{h_{E}}{n}+m_{\text {lat.av }}\right)\left[\frac{\sin \left(\delta+\varphi_{\text {fr }}+\beta_{1}\right)+\sin \left(\delta+\varphi_{f r}+\beta_{2}\right.}{\sin \left(\delta+\varphi_{f r}\right)}\right] .
$$




\section{Results}

To determine the influence of the pitch of the geokhod's external propeller on the energy capacity of rock breaking, we chose parameters of mining conditions for development of workings by the geokhod and geometrical parameters of the knife operating element. Values of these parameters are shown in Table 1.

Table 1. Mining conditions for development of workings by the geokhod and geometrical parameters of the knife operating element.

\begin{tabular}{|c|c|c|c|}
\hline Name & Designation & $\begin{array}{c}\text { Unit of } \\
\text { measure }\end{array}$ & Value \\
\hline Geokhod radius & $r_{2}$ & $\mathrm{~m}$ & 0.6 \\
\hline Generatrix radius & $r_{o}$ & $\mathrm{~m}$ & 0.05 \\
\hline $\begin{array}{c}\text { Coefficient taking into account the influence } \\
\text { of the cutting angle }\end{array}$ & $\varphi$ & $\mathrm{N} / \mathrm{m}^{2}$ & 0.59 \\
\hline $\begin{array}{c}\text { Specific cutting force in the frontal part of the } \\
\text { cut at the cutting angle of 45 }\end{array}$ & $m_{f}$ & $\mathrm{~N} / \mathrm{m}^{2}$ & 36,000 \\
\hline Soil breakout force in lateral sides of the cut \\
\hline $\begin{array}{c}\text { Specific cutting force of one of lateral edges } \\
\text { of the knife }\end{array}$ & $m_{l a t}$ & $\mathrm{~N} / \mathrm{m}$ & 8,490 \\
\hline $\begin{array}{c}\text { Angle of slope of the radial knife to the plane } \\
\text { perpendicular to the rotation axis of the } \\
\text { geokhod }\end{array}$ & $\gamma$ & degree & 0 \\
\hline Cutting angle & $\delta$ & degree & 25 \\
\hline Friction angle & $n$ & degree & 31.4 \\
\hline Number of knives the geokhod's OE & $k_{l a t}$ & degree & 30 \\
\hline $\begin{array}{c}\text { Depth coefficient of the expanding part of the } \\
\text { cut }\end{array}$ & $\gamma$ & 0.9 \\
\hline $\begin{array}{c}\text { Angle of slope of the expanding part of the } \\
\text { cut to the horizon }\end{array}$ & & & 300 \\
\hline
\end{tabular}

According to equations $(5,7,8)$, the dependence of the energy capacity of face rock breaking by the geokhod's knife operating element was determined, on the pitch of the external propeller $h_{E}$. Values of the external propeller's pitch vary from 0.05 to 2.25 with an interval of $0.05 \mathrm{~m}$.

Based on obtained values, the graph of the change in the energy capacity of face rock breaking by the geokhod's knife OE on change of the external propeller's pitch $h_{E}$ was plotted (Figure 3).

The ordinate axis of the represented dependence shows the value of the energy capacity of face rock breaking by the geokhod's knife operating element $\left(\mathrm{MJ} / \mathrm{m}^{3}\right)$, and the abscissa axis shows the change in the external propeller's pitch (m). 


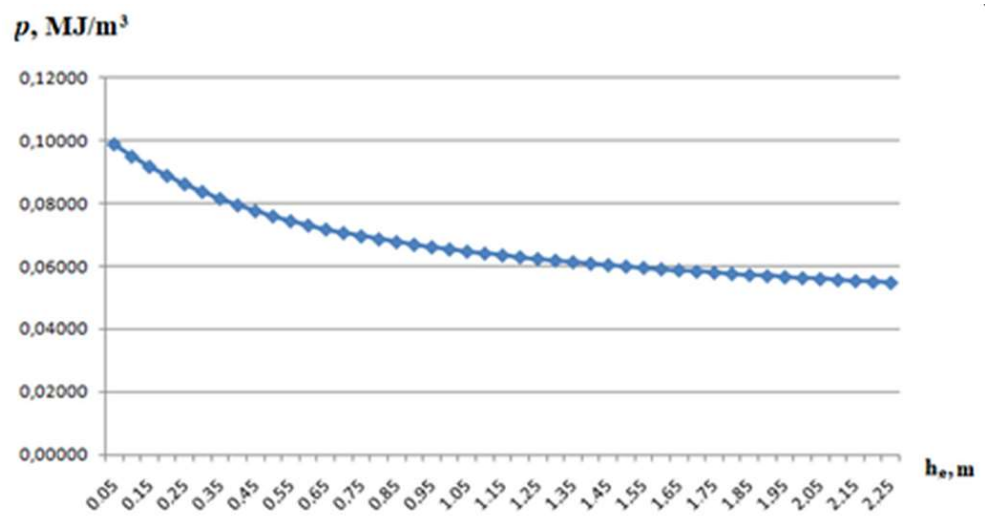

Fig. 3. Dependence of the energy capacity of face rock breaking by the geokhod's knife operating element on the external propeller's pitch.

The graph presented in Figure 3 shows that:

- the value of the energy capacity of face rock breaking by the geokhod's knife operating element decreases nonlinearly, as the external propeller's pitch increases from $0.05 \mathrm{~m}$ to $1 \mathrm{~m}$ by $0.035 \mathrm{MJ} / \mathrm{m}^{3}$;

- the energy capacity of face rock breaking by the knife operating element continues to decrease, but less intensively by the value of $0.01 \mathrm{MJ} / \mathrm{m}^{3}$, as the external propeller's pitch increases $\left(h_{E}>1.0 \mathrm{~m}\right)$;

- the energy capacity of face rock breaking decreases as a result of the relative increase in lateral expansions of the cut, within which the resistance of the rock is less than that in front of the frontal edge of the knife.

\section{Conclusions}

The method for determination of the energy capacity of face rock breaking by the geokhod's knife operating element was developed.

The dependence of the energy capacity of face rock breaking by the geokhod's knife operating element on the external propeller's pitch was obtained.

The energy capacity of face rock breaking by the geokhod's knife operating element decreases nonlinearly, as the pitch of the geokhod's external propeller increases.

\section{References}

1. V. Aksenov, V. Sadovets, D. Pashkov, E3S Web Conf., 21, 03008 (2017)

2. V. Aksenov, V. Sadovets, E. Rezanova, D. Pashkov, E3S Web Conf., 15, 03015 (2017)

3. V. Aksenov, V. Sadovets, D. Pashkov, E3S Web Conf., 41, 03002 (2018)

4. V.V. Aksenov, A.B. Efremenkov, V.Y. Sadovets, D.A. Pashkov, IOP Conference Series: Materials Science and Engineering, 441, 012002 (2018)

5. S. Nishi, T. Seiki, Mem. Sch. Eng. Nagoya Univ., 1, 235 (1997)

6. B. Maid, Hardrock Tunnel Boring Machines (Ernst \& Sohn, Berlin, 2008)

7. T. Wighman, ENR: News - Rec., 4, 156 (1998)

8. G. Brierley, World Tunnel. Subsurf. Excav., 9, 56 (1998)

9. A.B. Efremenkov, IFOST , 2:1, 348 (2011) 
10. J. Carmody, R. Sterling, Underground space design (Reinhold, New York,1993)

11. S.A. Zhironkin, A.A. Khoreshok, M.A. Tyulenev, G.A. Barysheva, M.C. Hellmer, IOP Conf. Ser.: Mater.Sci. Eng., 142, 012127 (2016)

12. M. Tyulenev, S. Zhironkin, K. Kolotov, E. Garina, Pollution Research, 35, 221 (2016)

13. V.Y. Begljakov, V.Y. Timofeev, M.V. Dokhnenko, Appl. Mech. Mater., 682, 282 (2014)

14. M.Y. Blashchuk, A.A.Kazantsev, R.V.Chernukhin, Appl. Mech. Mater., 682, 418 (2014)

15. Yu.V. Lesin, S.Yu. Luk'yanova, M.A. Tyulenev, J. Min. Sci., 46, 78 (2010)

16. A. Kazantsev, V.P. Kosykh, A.F. Revuzhenko, IOP Conference Series: Materials Science and Engineering, 91, 012089 (2015) 